\title{
Renal aspects of primary hyperparathyroidism
}

\author{
Jadwiga Szymczak, Anna Bohdanowicz-Pawlak, Joanna Jakubowska
}

\section{Department of Endocrinology, Diabetology and Isotope Treatment, Wroclaw Medical University, Poland}

Background

Nephrolithiasis and bone disease are the most common complications of primary hyperparathyroidism (PHPT).

The aim of this study was to evaluate the relationships between the existence of kidney stones, renal function and bone mineral density (BMD) in PHPT.

\section{Patients and methods} $\begin{array}{lcc}\text { Biomedical } & \text { evaluation, } & \text { BMD } \\ \text { measurements (DEXA, Lunar) and renal }\end{array}$ ultrasonography were performed in a group of 75 consecutive PHPT patients aged 57.6 \pm 12.7 years.

Exclusion criteria were other diseases and medications known to interfere with bone or mineral metabolism or renal function.

The control group consisted of 47 generally healthy volunteers. 30 patients with PHPT were subsequently investigated again one year after effective parathyroidectomy (PTX).

\section{Statistical analysis}

The data were analyzed using Statistica 10 (StatSoft Inc.). The statistical significance of differences between paired data was calculated using Wilcoxon's signed rank test and the Mann-Whitney $U$ test was used to compare values between different sample groups. Correlation coefficients were determined using Spearman's rank correlation. Statistical significance was defined as $p<0.05$. Laboratory methods

Serum and urinary solutes and alkaline phosphatase (ALP) were measured using standard laboratory methods.

Serum intact parathormone PTH was estimated with twosite immuno-chemiluminometric assay (Immulite 2000, DPC, Germany). Osteocalcin was estimated by IRMA using a kit (CISbio, France). The bone resorption marker ICTP (cross-linked carboxy terminal telopeptide of type I collagen) was estimated with an RIA kit (Orion Diagnostica). Osteoprotegerin was determined using a commercially available enzyme-linked immunosorbent assay (ELISA) (Biomedica Medizinprodukte GMBH, Vienna, Austria)

1,25-dihydroxy vitamin $\mathrm{D}$ and 25-hydroxy vitamin $\mathrm{D}$ plasma concentrations were measured using an RIA kit (DIASource ImmunoAssays S.A. Belgium)

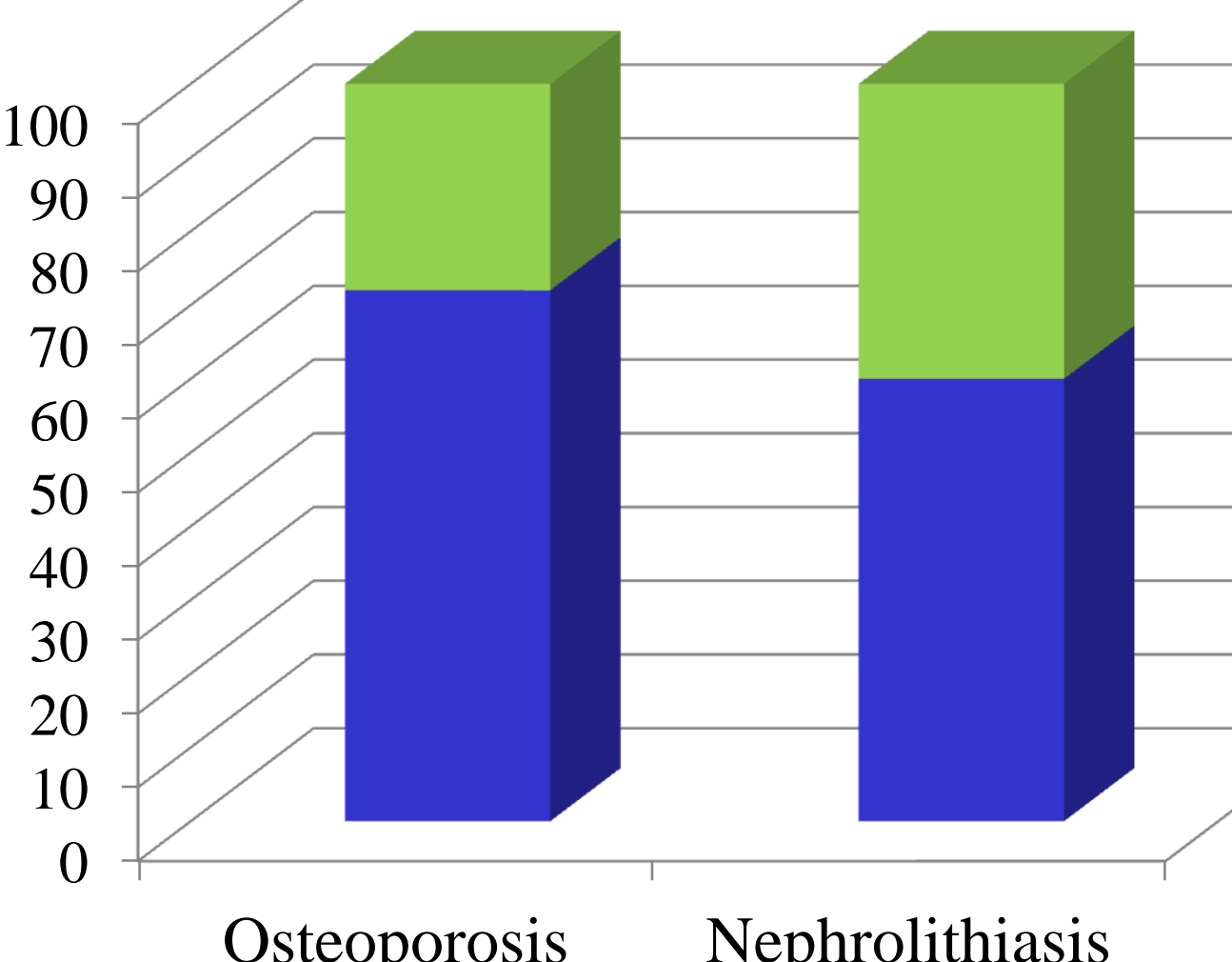

Fig.1 The prevalence of osteoporosis and nephrocalcinosis in patients with primary hyperparathyroidism

This work was supported by a grant from the Polish Ministry of Science and Higher Education (NN 402309536)

\section{Results}

\section{Conclusions}

1. Osteoporosis occurred in $72 \%$ and nephrolithiasis or nephrocalcinosis in $60 \%$ of patients with PHPT (fig.1).

2. The mean eGFR of the whole group was lower than in healthy controls (fig. 2)

3. eGFR was positively correlated with BMD (table 1).

4. eGFR was positively correlated with vitamin $1.25(\mathrm{OH})_{2} \mathrm{D}$ serum concentration and urine calcium excretion, but negatively with osteoprotegerin. No correlation was observed between eGFR PTH, serum calcium, Vitamin 25(OH)D and bone turnover markers (table2)

5. The presence of kidney stones was not associated with the severity of primary hyperparathyroidism as reflected in serum levels of PTH, calcemia, calciuria, bone turnover markers and BMD (table 3 and 4).

6. There was only a slight difference between the results of biochemical tests between patients with and without nephrolithiasis. In patients with nephrolithiasis serum $1,25(\mathrm{OH})_{2} \mathrm{D}$ concentration was higher $(p=0.02)$, phosphate concentration was lower $(p=0.01)$ and only a slight tendency to a higher eGFR and serum osteocalcin was observed (table 3 and 4).

7. In the group of 30 patients who were monitored for one year after PTX, GFR did not change, although the severity of nephrolithiasis decreased in $37 \%$ of them (fig. 3 ).

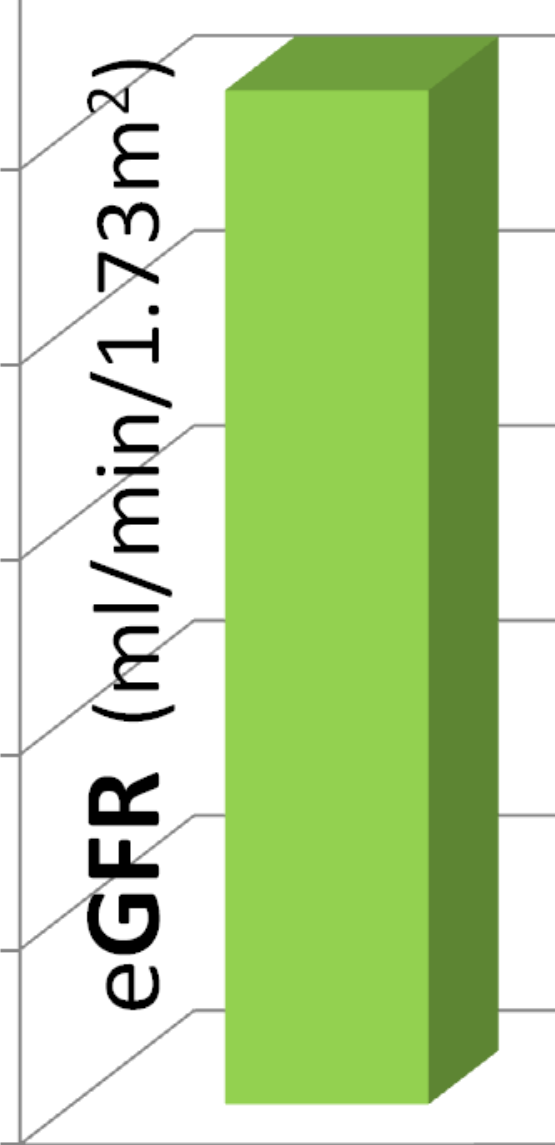

Control group

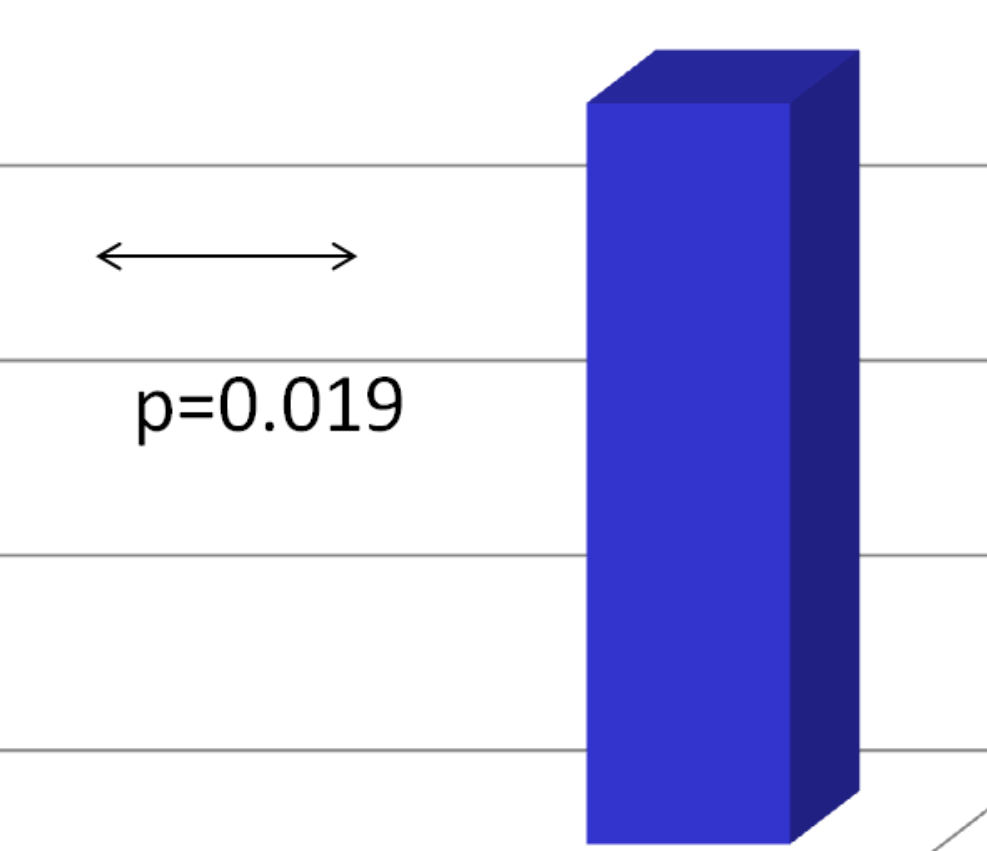

PHPT all
Nephrolithiasis or nephrocalcinosis
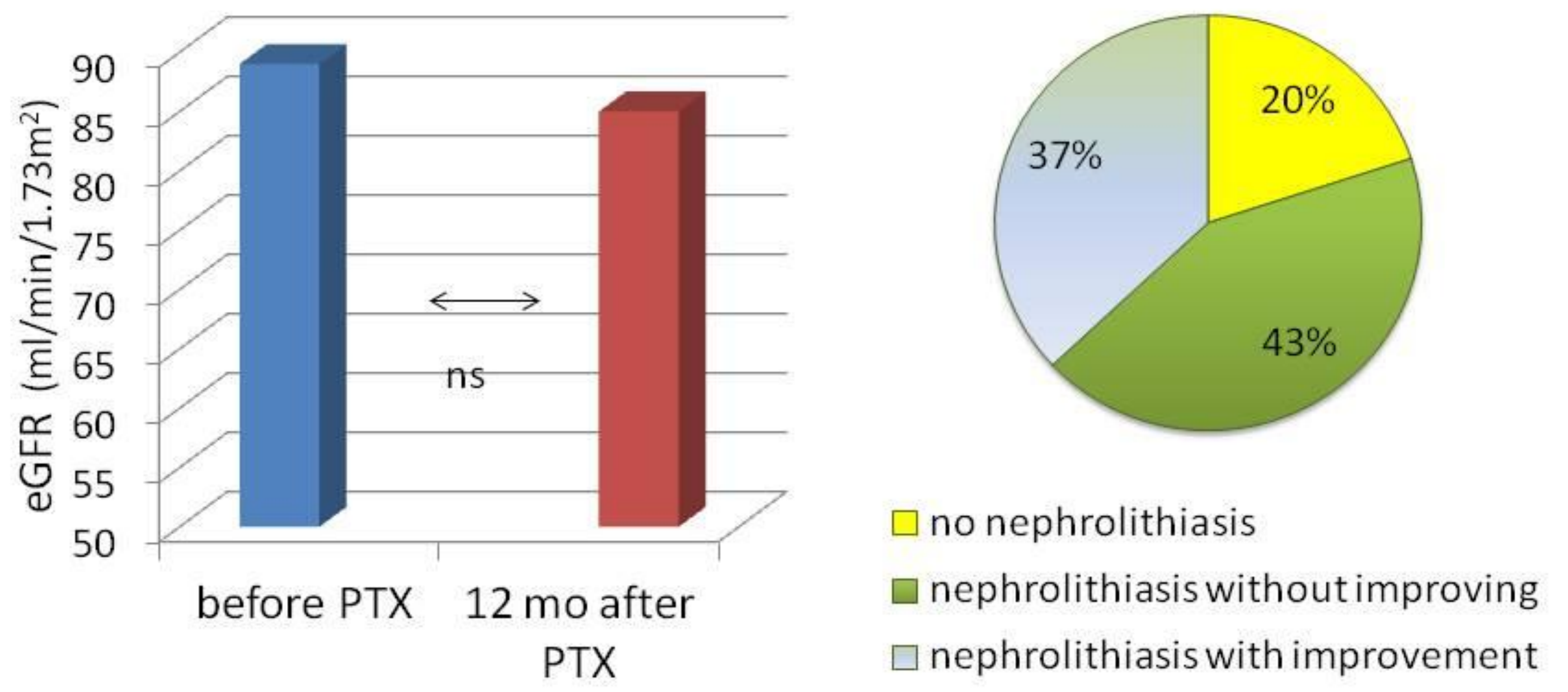

Fig. 3 The effect of parathyroidectomy on GFR and severity of nephrolithiasis in patients with PHPT $(n=30)$

Table 3. Demographic data and bichemical parameters for patients with PHPT-forming and non-forming renal stones.

\begin{tabular}{|c|c|c|c|}
\hline & $\begin{array}{c}\text { Nephrolithiasis or } \\
\text { nephrocalcinosis } \\
\quad N=45\end{array}$ & $\begin{array}{c}\text { No } \\
\text { nephrolithiasis } \\
N=30\end{array}$ & $P$ \\
\hline Age (yr) & $55.2 \pm 12.7$ & $61.2 \pm 12.1$ & ns \\
\hline BMI $\left(k g / m^{2}\right)$ & $26.2 \pm 4.4$ & $27.9 \pm 8.0$ & ns \\
\hline Calcium $_{\mathrm{s}}(\mathrm{mmol} / \mathrm{l})$ & $2.79 \pm 0.2$ & $2.77 \pm 0.36$ & ns \\
\hline Phosphate $_{\mathrm{s}}(\mathrm{mmol} / \mathrm{l})$ & $0.73 \pm 0.1$ & $0.84 \pm 0.2$ & 0.01 \\
\hline eGFR $\left(\mathrm{ml} / \mathrm{min} / 1.73 \mathrm{~m}^{2}\right)$ & $91.2 \pm 26.9$ & $84.1 \pm 32.6$ & $\begin{array}{l}\text { Ns } \\
\text { (0.12) }\end{array}$ \\
\hline Creatinine $_{\mathrm{s}}(\mathrm{umol} / \mathrm{l})$ & $71.5 \pm 18.1$ & $73.1 \pm 11.9$ & ns \\
\hline Urine calcium (mmol/d) & $8.04 \pm 3.7$ & $8.0 \pm 3.7$ & Ns \\
\hline
\end{tabular}

1. Routine 24-hour urine calcium evaluation cannot predict which patients with primary hyperparathyroidism will have kidney stones.

2. Nephrolithiasis does not appear to be the only cause of GFR reduction in PHPT.

3. There is no clear correlation between BMD and the formation of kidney stones, but there is a positive relationship between BMD and renal function.

4. Since there is no guarantee that the reduction in GFR in symptomatic PHPT is reversible after PTX, decisions regarding surgery should not be delayed even in mild cases.

Table 1. Spearman's rank correlation coefficients for the association of eGFR with age and bone mineral density in PHPT patients $(n=75)$

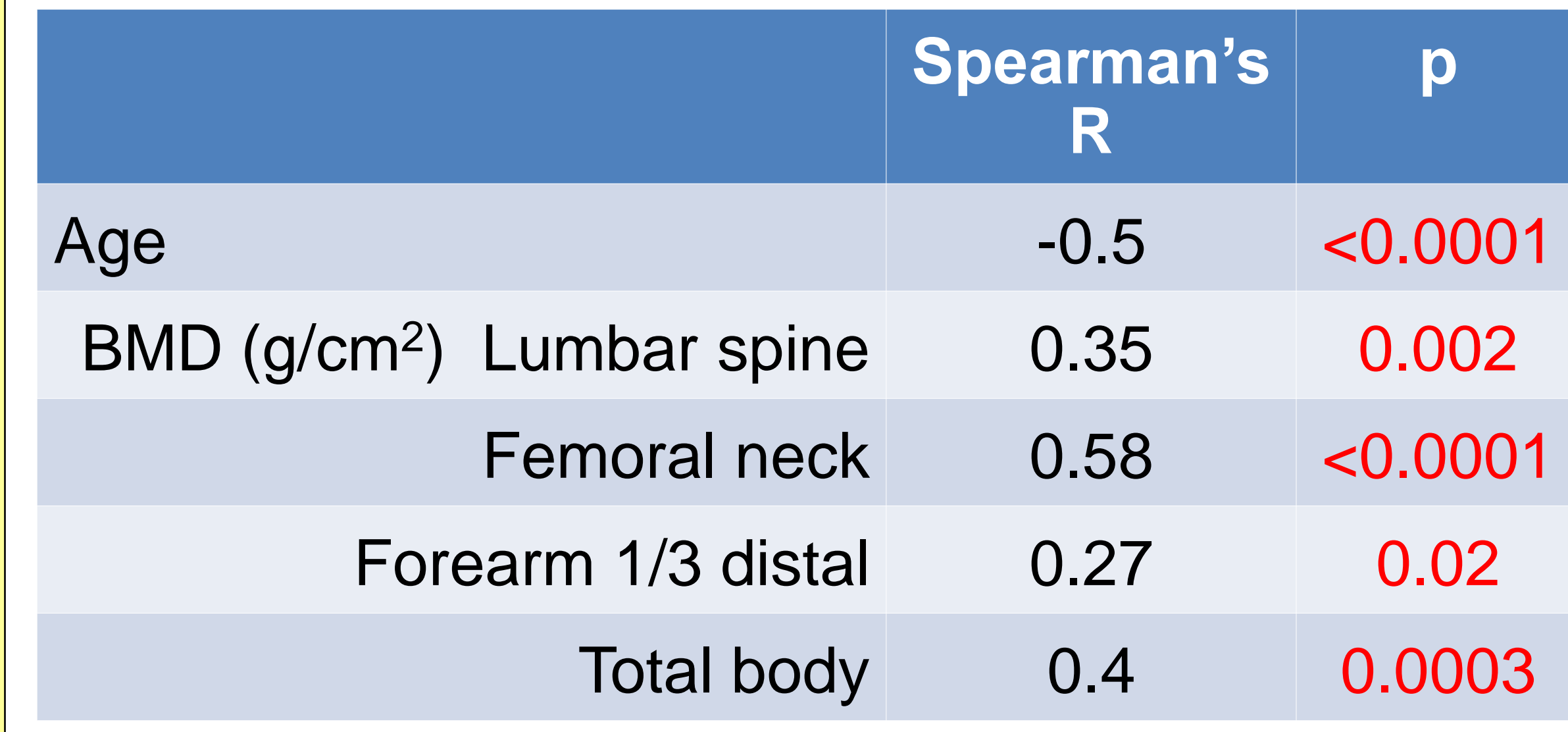

Table 2. Spearman's rank correlation coefficients for the association of eGFR with biochemical parameters in PHPT patients $(n=75)$

\begin{tabular}{lcc} 
& $\begin{array}{c}\text { Spearman's } \\
\mathbf{R}\end{array}$ & $\mathbf{p}$ \\
\hline 24 h urine calcium & 0.51 & $<0.0001$ \\
Vitamin $1,25(\mathrm{OH})_{2} \mathrm{D}$ & 0.39 & 0.0007 \\
\hline Osteoprotegerin $(\mathrm{n}=30)$ & -0.3 & 0.01 \\
Parathormone & 0.08 & 0.5 \\
\hline Osteocalcin & 0.02 & 0.8 \\
\hline Serum calcium & -0.036 & 0.7 \\
Serum phosphate & -0.04 & 0.7 \\
ALP & 0.13 & 0.28 \\
ICTP & -0.01 & 0.9 \\
Vitamin 25(OH)D & -0.17 & 0.16
\end{tabular}

Table 4. Bone mineral density (BMD), vitamin $\mathrm{D}$ and bone turnover markers in patients with primary hyperparathyroidism forming and non-forming renal stones (mean $\pm \mathrm{SD}$ )

\begin{tabular}{|c|c|c|c|}
\hline & $\begin{array}{l}\text { Nephrolithiasis } \\
\text { or } \\
\text { nephrocalcinosis } \\
N=45\end{array}$ & $\begin{array}{c}\text { No } \\
\text { nephrolithiasis } \\
N=30\end{array}$ & $\mathrm{P}$ \\
\hline \multicolumn{4}{|l|}{$\mathrm{BMD}\left(\mathrm{g} / \mathrm{cm}^{2}\right)$} \\
\hline Lumbar spine & $0.99 \pm 0.17$ & $0.96 \pm 0.17$ & ns \\
\hline Femoral neck & $0.81 \pm 0.11$ & $0.78 \pm 0.14$ & ns \\
\hline Forearm distal & $0.53 \pm 0.12$ & $0.51 \pm 0.11$ & ns \\
\hline Total body & $0.98 \pm 0.12$ & $0.97 \pm 0.13$ & ns \\
\hline Osteocalcin (ng/ml) & $48.6 \pm 30.5$ & $45.9 \pm 71.0$ & ns \\
\hline ALP (U/I) & $150.9 \pm 71.3$ & $147.4 \pm 85.1$ & ns \\
\hline $\begin{array}{l}\text { Osteoprotegerin } \\
\text { (pmol/l) }\end{array}$ & $5.55 \pm 1.6$ & $6.2 \pm 1.6$ & $\begin{array}{l}0.09 \\
\text { (ns) }\end{array}$ \\
\hline ICTP $(\mu \mathrm{g} / \mathrm{ml})$ & $5.83 \pm 4.1$ & $5.6 \pm 4.26$ & ns \\
\hline $\begin{array}{l}\text { Vitamin 25(OH)D } \\
\text { (ng/ml) }\end{array}$ & $31.7 \pm 23.0$ & $27.2 \pm 16.6$ & ns \\
\hline $\begin{array}{l}\text { Vitamin } 1,25(\mathrm{OH})_{2} \mathrm{D} \\
(\mathrm{pg} / \mathrm{ml})\end{array}$ & $57.3 \pm 21.7$ & $47.1 \pm 14.1$ & 0.02 \\
\hline
\end{tabular}

